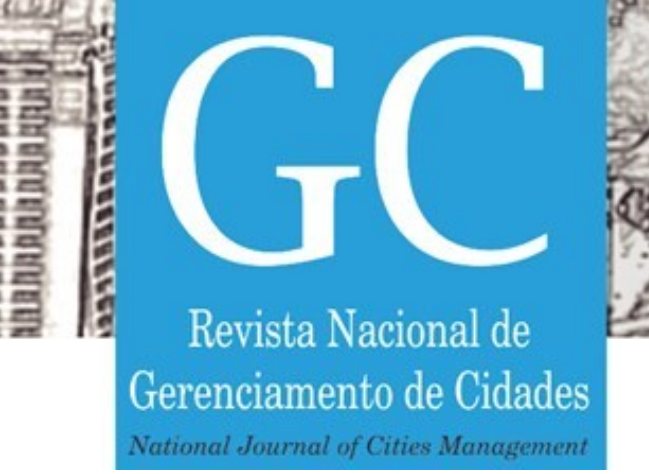

\title{
Dinâmica fluvial no espaço urbano: aspectos relevantes
}

Fluvial dynamics in urban space: relevant aspects

Dinámica fluvial en el espacio urbano: aspectos relevantes

Sandra Medina Benini

Pós-doutorado pelo PPGARQ-UNESP, bolsista PNPD/Capes, Doutorado em Arquitetura e Urbanismo pela UPM e Doutorado em Geografia pela FCT-UNESP. arquiteta.benini@gmail.com

Jeane Aparecida Rombi de Godoy Rosin Pós-doutoranda pelo PPGARQ-UNESP. Doutorado em Arquitetura e Urbanismo pela UPM. jeanerosin@terra.com.br 


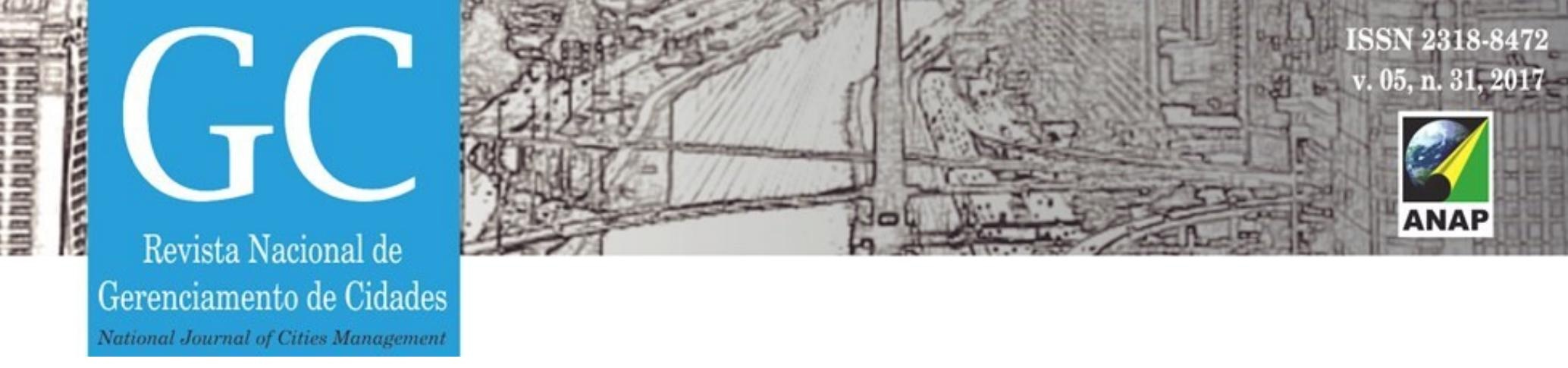

\section{RESUMO}

Este artigo tem por objetivo realizar uma reflexão quanto à dinâmica fluvial em cidades, com enfoque no dilema das inundações urbanas, que vem colocando em xeque os atuais modelos de políticas urbanas, principalmente as habitacionais e ambientais. Para tanto, foram analisados diversos estudos e pesquisas acadêmicas já realizadas, as quais apontaram que as áreas de preservação permanente urbanas, comumente ocupadas por extratos sociais de menor poder aquisitivo, são as aquelas que apresentam caráter geomorfológico vulnerável, passiveis da ocorrência de inundação. Sem desconsiderar a relevância de implementação dessas políticas públicas, não se pode também, deixar de considerar entre suas diversas facetas, a omissão e o descaso dos administradores públicos diante, não apenas dos impactos ambientais dos diversos sistemas que são de vital importância para o equilíbrio do meio urbano e ainda das grandes possibilidades de riscos oferecidas nestas localidades, relacionadas à ocorrência de acidentes ambientais.

Palavras-chave: Política Pública; Riscos Ambientais; Inundações.

\section{SUMMARY}

This article aims to reflect on the river dynamics in cities, focusing on the dilemma of urban floods, which has put in check the current models of urban policies, especially housing and environmental. In order to do so, a number of studies and academic research have already been carried out, which pointed out that the permanent urban preservation areas, commonly occupied by social extracts of lower purchasing power, are those that present a vulnerable geomorphological character, subject to the occurrence of flooding. Without neglecting the relevance of implementing these public policies, one can not fail to consider among its many facets the omission and neglect of public administrators, not only of the environmental impacts of the various systems that are of vital importance for the balance of urban environment and also the great possibilities of risks offered in these localities, related to the occurrence of environmental accidents.

Keywords: Public Policy; Environmental Risks; Floods.

\section{RESUMEN}

Este artículo tiene por objetivo realizar una reflexión sobre la dinámica fluvial en ciudades, con enfoque en el dilema de las inundaciones urbanas, que viene colocando en jaque los actuales modelos de políticas urbanas, principalmente las habitacionales y ambientales. Para ello, se analizaron diversos estudios e investigaciones académicas ya realizadas, las cuales apunta que las áreas de preservación permanente urbanas, comúnmente ocupadas por extractos sociales de menor poder adquisitivo, son aquellas que presentan carácter geomorfológico vulnerable, pasibles de la ocurrencia de inundación. Sin olvidar la relevancia de implementación de esas políticas públicas, no se puede tampoco dejar de considerar entre sus diversas facetas, la omisión y el descuido de los administradores públicos frente, no sólo de los impactos ambientales de los diversos sistemas que son de vital importancia para el equilibrio del equilibrio el medio urbano y las grandes posibilidades de riesgos ofrecidos en estas localidades, relacionadas con la ocurrencia de accidentes ambientales.

Palabras clave: Política Pública; Riesgos Ambientales; Inundaciones. 


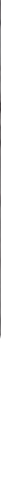

\section{INTRODUÇÃO}

Este artigo aborda a temática das águas urbanas propondo algumas reflexões quanto à dinâmica fluvial em cidades, com enfoque no dilema das inundações urbanas, que vem colocando em xeque os atuais modelos de políticas urbanas, principalmente as habitacionais e ambientais.

Ao se discutir a questão das águas urbanas, é imprescindível considerar não apenas o uso e ocupação do solo urbano, mas essencialmente, a evolução da dinâmica fluvial dos cursos d'água, tanto para as variáveis como no estabelecimento de parâmetros de restrições. Deste modo, o conhecimento da dinâmica fluvial deve ser considerado como pré-requisito para tomada de decisões políticas, administrativas e técnicas, quando objetivem o planejamento urbano de assentamentos ao longo dos cursos d'águas, visto que as populações residentes nesses locais estão sujeitas a inúmeros riscos ambientais, dentre os quais, destacam-se as inundações.

Como procedimento metodológico adotou-se uma pesquisa qualitativa sobre a temática proposta, onde consistiu no exame da literatura pertinente de trabalhos científicos (livros, teses, dissertações, artigos, etc.) e da legislação urbanística e ambiental em vigor.

\section{CIDADE E O RIO}

As cidades são "palcos de problemas sociais, econômicos e ambientais, principalmente nos países em desenvolvimento", como o Brasil, onde as "disparidades sociais e carências de recursos financeiros e técnicos para equacionar as questões de infraestrutura urbana e gestão ambiental são mais acentuadas" (GORSKI, 2010, p. 23). Um dos maiores desafios dos gestores públicos é de conciliar os impactos ambientais oriundos do processo de urbanização com a preservação ambiental. Swyngedouw (2001, p.84) considera que a cidade, a sociedade e a natureza, são representações "inseparáveis, mutuamente integradas, infinitamente ligadas e simultâneas, responsáveis pelas contradições, tensões e conflitos".

Braga (2003) esclarece que essa conjuntura apresentada por Swyngedouw (2001), faz parte da dinâmica das cidades, como por exemplo, os conflitos sócio-ambientais oriundos do parcelamento do solo urbano.

[...] o avanço da urbanização sobre o meio natural, de maneira desordenada, tem causado a degradação progressiva das áreas de mananciais remanescentes, com a implantação de loteamentos irregulares e a instalação de usos e índices de ocupação incompatíveis com a capacidade de suporte do meio. O parcelamento indiscriminado do solo nas periferias urbanas é uma das principais fontes de problemas ambientais das cidades. (BRAGA, 2003, p.113).

Neste sentido as ocupações em áreas de mananciais são apenas parte do problema, pois as "alterações decorrentes do uso do solo, como a retirada da vegetação [...] e a impermeabilização do solo [...], causam um dos impactos humanos mais significativos no ciclo hidrológico", como por exemplo, os problemas de drenagem urbana - inundação. (BRAGA, 2003, p.114-115). 


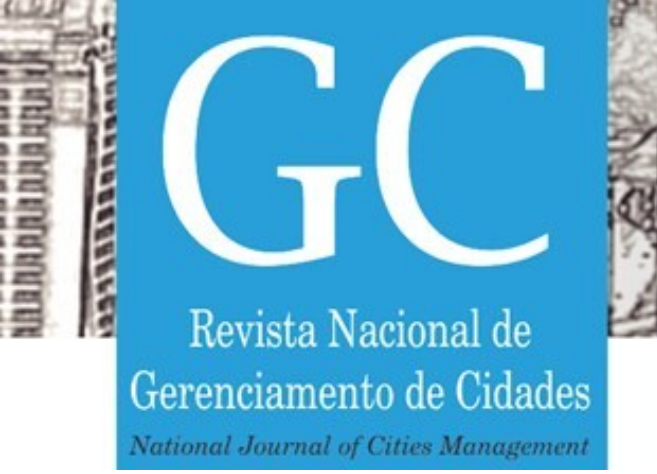

A ocupação e o uso do solo urbano de forma desordenada criaram espaços com os mais diversos problemas ambientais e, entre tais situações, a drenagem da água pluvial está presente em quase todas as cidades brasileiras.

Segundo Coelho (2005, p.28), as "cidades historicamente localizaram-se às margens de rios", onde em regra, as "inundações continuam e vitimam as classes pobres". Selles et al. (2001) esclarecem que muitos córregos e rios ao longo das décadas de 80 e 90 do século XX, sofreram modificações para se adequarem às novas configurações urbanas das cidades e que o sistema de drenagem urbana foi transformado com a finalidade de acelerar o transporte das águas pluviais, pois muitas baixadas úmidas foram drenadas para o uso agrícola ou assentamento humano e muitos rios e córregos foram retificados para a construção de estradas e vias férreas.

Para Selles et. al (2001, p.09), na "maior parte das intervenções só foram considerados os aspectos setoriais e negligenciados, os aspectos culturais, sanitários, ecológicos, urbanísticos e paisagísticos". Neste contexto, dentre as possíveis soluções encontradas por muitos gestores públicos, "a canalização dos córregos e rios urbanos" tem sido a mais recorrente, pois facilita e acelera o "escoamento superficial das águas, transformando-os em meros transportadores de efluentes municipais" (SANTOS et. al, 2008, p.1514).

Pitton (2003, p.38) salienta que o ambiente natural, ora presente nos aglomerados urbanos, tende ao desaparecimento, "sobrepujado pelas formas concretas de ocupação do território (rios canalizados, vegetação derrubada, solo impermeabilizado, entre outras)". Para Ferreira e Francisco (2003) esse fenômeno é decorrente da carência de institutos legais incapazes de responder a demanda socioambiental presente nas cidades brasileiras.

\section{INUNDAÇÃO}

Cada vez mais, uma parcela significativa da população urbana, principalmente aquela residente em fundos de vales, tem vivenciado o terror de ter suas casas e pertences destruídos por fortes inundações. Devido à freqüência com que têm ocorrido os eventos desta natureza, muitos estudos referentes à questão afirmam que os mesmos além de estarem fortemente vinculados às condições geomorfológicas da área de incidência, estão intrinsecamente relacionados a vulnerabilidade social dos segmentos de menor poder aquisitivo, principalmente aqueles residentes em assentamentos precários, via de regra, localizados em áreas de risco.

\footnotetext{
No caso dos municípios com problemas de inundação, aproximadamente $25 \%$ atribuíram o fato a degradação de áreas protegidas e a ocupação irregular de áreas frágeis e $30 \%$ ao desmatamento. Em síntese, os processos como deslizamento de encostas, inundações e erosão estão fortemente associados à degradação de áreas frágeis, potencializada pelo desmatamento e ocupação irregular. (MAFFRA; MAZZOLA, 2007, p.10).
}

A cidade apresenta uma dinâmica geomorfológica própria, à medida que o espaço urbano é modificado, há um impacto direto no contexto espacial, criando uma nova dinâmica para as interrelações urbanas, como por exemplo, o surgimento de áreas de alagamentos e inundação. 


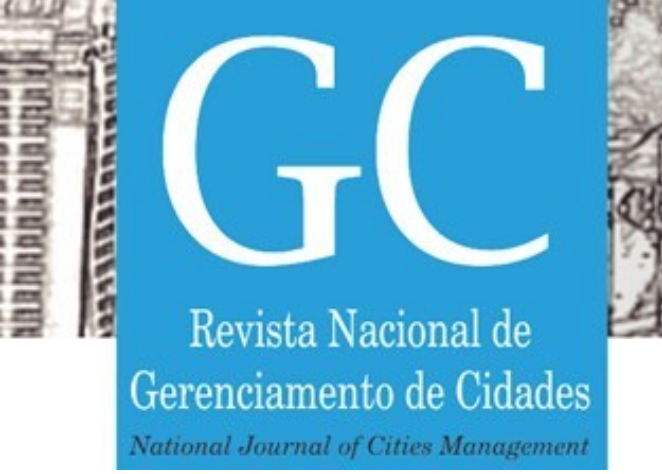

FERREIRA, R. C.; FRANCISCO, J. A legislação ambiental e urbanística no trato das fronteiras d'água. In: BRAGA, R.; CARVALHO, P. F. C. (Org.). Recursos Hídricos e Planejamento Urbano e Regional. Rio Claro: Laboratório de Planejamento Municipal - Deplan - UNESP - IGCE, 2003. p. 87 - 105.

GORSKI, Maria Cecília Barbieri. Rios e cidades. São Paulo: Editora Senac São Paulo, 2010.

MAFFRA, Cristina Q.T.; MAZOLLA, Marcelo. As razões dos desastres em território brasileiro. In: SANTOS, Rozely Ferreira dos (Org.) Vulnerabilidade Ambiental: desastres naturais ou fenômenos induzidos?. 1a ed. Brasília: Ministério do Meio Ambiente, 2007.

PITTON, Sandra Elisa Contri. A água e a cidade. In: BRAGA, R.; CARVALHO, P. F. C. (Org.). Recursos Hídricos e Planejamento Urbano e Regional. Rio Claro: Laboratório de Planejamento Municipal - Deplan - UNESP - IGCE, 2003. p. $37-47$.

ROSIN, Jeane Aparecida Rombi de Godoy. Áreas de Preservação Permanente e as Dinâmicas Urbanas e Socioambientais: Avanços e Desafios das Políticas de Proteção e Recuperação aos Mananciais. Tese (Doutorado em Arquitetura e Urbanismo) - Universidade Presbiteriana Mackenzie, São Paulo, 2016.

SANTOS, R. M.; ECHEVERRIA, J. L.; BENINI, S. M. Revitalização de córregos como estratégia de controle de inundações em áreas urbanas. V Seminário Latino-americano e I Seminário Ibero-americano de Geografia Física. Santa Maria - Rio Grande do Sul - Brasil, 2008.

SELLES, I. M. et al.. Revitalização de rios - orientação técnica. Rio de janeiro. SEMADS. Cooperação Técnica Brasil - Alemanha. Projeto PLANÁGUA-SEMADS/ GTZ. 2001.

SWYNGEDOUW, Erik. A cidade como um híbrido: natureza, sociedade e "urbanização-cyborg". In: ACSELRAD, Henri (Org.). A duração das cidades: sustentabilidade e risco nas políticas urbanas. Rio de Janeiro: DP\&A, 2001. p. 83-104.

TUCCI, Carlos E. M. Gestão de Águas Pluviais Urbanas. Ministério das Cidades - Global Water Partnership Wolrd Bank - Unesco, 2005. Disponível em <http://4ccr.pgr.mpf.gov.br/institucional/grupos-detrabalho/residuos/docs_resid_solidos> Acesso em 04 jan. 2011. 